\title{
Experimental Design and Technical Tools for the Research of Musical Stimuli with Artificially Implemented Complexity Used in the Rehabilitation of Alzheimer's Disease Patients ${ }^{1}$
}

\section{Lenka Dohnalová, Tomáš Fürst}

\section{Introduction}

This interdisciplinary research investigates rehabilitation strategies based on the empirically validated effects of musical stimuli in patients with neurological problems, which was inspired by the research of Nicholas Stergiou (Biomechanics Lab, University of Nebraska in $\mathrm{Omaha}^{2}$ ), a pioneer of new rehabilitation methods. These methods are based on signals (sound, visual stimuli, tactile stimuli) specifically containing artificially implemented physiological complexity (e.g. pink noise). In other words, the physiological signals (ECG, EEG, walking rhythm) of a healthy organism exhibit a certain degree of complexity, therefore the signal is neither too simple (for example, recurring), nor too random (such as white noise). The optimal degree of complexity is difficult to quantify, although several new mathematical tools, such as the Multiscale Entropy Analysis ${ }^{3}$ and Detrended Fluctuation Analysis ${ }^{4}$, are already available. The so-called pink noise is a random signal with a frequency response in which the power spectral density

\footnotetext{
${ }^{1}$ The research is part of the first author's $\mathrm{PhD}$. thesis and is financially supported by UP (Specific research IGA PdF 2016 11).

${ }^{2}$ Nathaniel Hunt, Denise McGrath and Nicholas, "The Influence of Auditory-motor Coupling on Fractal Dynamics in Human Gait," in Scientific Reports, no. 4 (2014): accessed July 30, 2016, doi:10.1038/srep05879

${ }^{3}$ Magdalena Costa, Ary L. Goldberger and C. K. Peng, "Multiscale Entropy Analysis of Biological Signals," in Physical Review E 71, no. 2 (2005): accessed December 20, 2016, doi: 10.1103/ PhysRevE.71.021906.

${ }^{4}$ Jan W. Kantelhardt et al., "Multifractal Detrended Fluctuation Analysis of Nonstationary Time Series," in Physica A 316, no. 87 (2002): accessed December 20, 2016, doi: 10.1016/S03784371(02)01383-3.
} 
is inversely proportional to the frequency of the signal. This type of noise surprisingly occurs in many biological systems - e.g. in the rhythm of heart activity, the activity of the human brain or in DNA sequence statistics. ${ }^{5}$ In addition, with biological aging and diseases, physiological complexity decreases (e.g. in the dynamics of the heart rate, breathing, or walking ${ }^{6}$ ) which is an aspect that corresponds substantially to the research intent to build this complexity into recordings of classical music.

One of the possible approaches is to incorporate pink noise disturbance in parts of musical works, which would then be used in therapy and education. The potential use of stimuli modified in this way could be very extensive. Its application is evident wherever the effect of music therapy methods is empirically documented-in patients with Alzheimer's disease, but also in children suffering from neurodevelopmental disorders, such as ADHD, where methods of group educational therapy are commonly used, as well as in children with autism spectrum disorder, whose orientation in time, space and the sequence of activities can be improved by these methods.

The target group in the research project will be selected from among patients in the first stage of Alzheimer's disease. This disease belongs among the serious neurodegenerative brain diseases, in which the patient is afflicted with dementia ( $\mathrm{AD}$ is the reason for 60 to 70 percent of dementia cases ${ }^{7}$ ). It is estimated that the number of people with dementia in the Czech Republic numbers at approximately $150,000 .{ }^{8}$ The increase in the incidence of this disease is worrying; in the next thirty years it is expected that the world population afflicted with the disease will quadruple. Although many research groups are attempting to find a treatment that would eliminate harmful beta amyloid plaques, no effective cure for the disease has been found yet. ${ }^{9}$ The only viable option left is slowing down the progression of the disease and the use of various rehabilitation methods that help to train and maintain the basic cognitive functions: thinking, memory, and judgement. The level of the patient's cognitive skills, such as memory, attention, logical reasoning and the ability to perform motor skills, are assessed by standardized tests (Addenbrooke's Cognitive Examination, Activity of Daily Living,

5 Paavo Pylkkänen and Pauli Pylkkö, New Directions in Cognitive Science: Proceedings of the International Symposium, 4-9 August 1995, Saariselkä, Lapland, Finland (Helsinki: Finnish Artificial Intelligence Society, 1995), 280-285.

${ }_{6}^{6}$ Brad Manor et al., "Physiological Complexity and System Adaptability: Evidence from Postural Control Dynamics of Older Adults," in Journal of Applied Physiology 109, no. 6 (2010), accessed June 20, 2016, doi: 10.1152/japplphysiol.00390.201.

7 "Dementia Fact sheet," World Health Organization, accessed July 30, 2016, http://www.who.int/ mediacentre/factsheets/fs362/en/.

${ }^{8}$ Ibid.

${ }^{9}$ Ibid. 
Mini-Mental State Examination (MMSE), the Montreal Cognitive Assessment $(\mathrm{MoCA} \text { test })^{10}$.

It can be seen in patients' case studies of Alzheimer's disease (as well as Parkinson's disease) that music is a fundamental therapeutic tool for these patients. The acclaimed British neurologist Dr. Oliver Sacks, the recently deceased professor of the NYU School of Medicine, stated that these patients' responsiveness to music is immense; although many often suffer from aphasia already, they can sing and play musical instruments. In his inspiring book "Musicophilia:Tales of Music and the Brain"11 he suggests that "music therapy can aid these patients, because the musical perception, musical sensibility, musical emotion and musical memory can survive long after other forms of memory disappeared". ${ }^{12}$ From this perspective, work with musical stimuli becomes the only education these patients are capable of.

There is a lot of evidence of the effectiveness of art therapy methods in the treatment of chronic patients. Besides the available scientific publications, a wide range of art therapy in nursing homes or day care centres can be observed. This refers to art therapy in a narrow sense: music therapy, drama therapy, and dance and movement therapy.

Therefore, our research objective will be to work with patients in the first stage of $\mathrm{AD}$, using musical stimuli enriched with a complexity of physiological nature, and subsequently it will assess, using standardized tests, whether their cognitive functions have been improved. This improvement can be quantified in relation to a control group which undergoes therapy with musical stimuli, but without the implemented physiological complexity. The need to approach the topic in its complexity has led us to utilize the most objective method possible, which is quantitative research conducted in the form of an experiment based on an empirical analysis of the processes and phenomena. Due to the interdisciplinary nature of the topic, it is necessary to build a team comprising a neurologist, a psychologist and a mathematician, who will cooperate with music therapists and music teachers. When working with patients, controlling all the variables that could affect the cause and effect relationship will be very difficult. Consequently, determining the exact diagnosis of $\mathrm{AD}$ completely, especially in patients at an early stage of the disease, with whom we are going to work, will be almost impossible. Finding comparable groups of patients, experimental and

\footnotetext{
10 “Tests used in diagnosing dementia," Alzheimer's Australia, accessed December 14, 2016, https://www.fightdementia.org.au/sites/default/files/helpsheets/Helpsheet-DementiaQandA10TestsUsedInDiagnosingDementia_english.pdf.

${ }_{11}$ Oliver Sacks, Musicophilia: Tales of Music and the Brain, (Prague: Dybbuk, 2009), 325-337.

12 Sacks, Musicophilia, 326.
} 
control groups, will also be very difficult. The cause and effect relationship between variables may interfere with both situational and time factors.

This study deals with implementing the pre-research stage of the project, in which software enabling the implementation of rhythmic disorder such as pink noise into musical works has been created. A pilot study in a group of healthy respondents has been performed to determine what level of rhythmic disorder is still acceptable and undisturbing.

\section{Methods}

Creating the skills to build physiological complexity into a music recording in MIDI format is crucial.

The MIDI format includes a time record of individual events, which is most suitable for our purposes. An event means, for example, the beginning or ending of a tone or the pressing of a pedal. A MIDI recording can contain multiple tracks. Working with WAV is also possible, but technically so demanding that it exceeds our capacity.

Since a recording that includes relatively few tracks is to be used, a piano piece has been chosen. This instrument is convenient for us, as far as the tonal dynamics is concerned (clear attack and quick reverberation). Very good quality piano samples are essential. In poorer quality pieces, the subjects would focus on the unnatural sounds of the instruments and would not be able to distinguish the disruptive influence of rhythmic anomalies.

Owing to the generational and mental characteristics of the elderly, clear and optimistic Mozart's Sonata Facile (Piano Sonata No. 16 in C major, K. 545) has been chosen. ${ }^{13}$ The MIDI format contains four tracks (channels), one for the pace record, one for the left hand, one for the right hand and one for the "controller", in our case the right pedal. The MIDI file is quantized (tempo is mechanically precise), but the first track contains its modulation in order for the recording to sound natural.

The track for the left hand is rhythmically more important. It is necessary first to set up the rhythm to be completely regular. This is done in order to control what kind of rhythmic disturbances need to be used. In this case, it is rather trivial because it is enough to ignore the first track, which contains a modulation of machine-precise tempo. The other tracks are already rhythmically aligned (quantized) in this way. If the recording is not aligned, it needs to be quantized. Our software (written in MatLab) performs the comparisons as follows: the track

13 “Database midi file," accessed August 3, 2016, http://www.piano-midi.de/midisearch.php?composer=14\&formSubmit=Search\&user=\&count. 
for the left hand selects all events of the note-on type that have non-zero value, thus correspond to the tone beginning (the events of note-on type zero value designate the tone ending). The difference between these events is computed and a basic duration is found (in our case it corresponds to the sixteenth note time). All the chords (events in almost identical time) are aligned to the same time, and all the intervals are aligned to be multiples of the basic duration. It may occur that an interval deviates from the structure of the multiples of fundamental duration, which might indicate a decoration, or a triplet. These events are deemed special and are left unchanged for the time being.

After the fundamental rhythm of the left hand is aligned, the right hand, the controller, special events in the left hand, and any other events contained in MIDI must be adjusted to this alignment, which is performed by simple linear interpolation. Let us assume, for example, that the time of the following three events was [100 110 150], where the first and the third event is the tone of the left hand and the middle tone event is the tone of the right hand. Let us suppose that after the alignment, the time of the first event will be 105, and the third time will be 160 . The time of the middle event will then be changed to the value of $x$, thus $(110-100) /(150-100)=(x-105) /(160-105)$. All the events in the right-hand track, the controller track, and in addition, the special tones in the left-hand track and any other MIDI events, are interpolated in this way.

Thus, a reasonably quantized MIDI recording can be obtained, and it is then possible to proceed to the application of a rhythmic disturbance with physiological complexity to this file. For our purposes, a time series of RR intervals based on a healthy human heart, which can be obtained on the Physionet platform, ${ }^{14}$ has been used. The time series has been rescaled in order for the average duration of RR intervals to match the duration of a one sixteenth note time. Let us call this modified series A. A sequence of intervals of equal length has been taken as series $\mathrm{B}$, each of them equals to one sixteenth note time. Convex combination $\mathrm{C}^{*}=\mathrm{T} \mathrm{A}+(\mathrm{t}-1) * \mathrm{~B}$ then equals to the varied disturbance amplitude with physiological complexity. The quantized MIDI recording for $t=0$ is not changed (the duration of all intervals will remain the same, the disturbance amplitude is zero) and for $\mathrm{t}=1$, the duration of the intervals at the maximum rate is changed, thus the duration of the sixteenth note time equals to the duration of a healthy heart's beat (amplitude is maximal). By a continuous transition from $t=0$ to $\mathrm{t}=1$, any desired disturbance amplitude with physiological complexity can be achieved. The algorithm of the implementation of physiological complexity to the recordings is described below.

${ }^{14}$ PhysioNet: “The Research Resource for Complex Physiologic Signals," PhysioNet, accessed August 3, 2016, https://www.physionet.org/tutorials/fmnc/node8.html. 
The track corresponding to the left hand, which is rhythmically more important, is selected and the tones corresponding to the beginnings of quaver times are chosen. The beginnings of these "heavy" beats are moved to the time deducted from the corresponding index of the above calculated of time series $\mathrm{C}$. Thus, the foundation of a new track which will contain the desired amount of physiological complexity is obtained. The remaining MIDI events of the left hand (tone endings, light beats, decorations, triplets, etc.) are modified by linear interpolation, as explained above. For example, let us assume that the time of the three subsequent events was $[100,110,150]$, where the first and the third event is the tone of the left hand on the heavy beat and the middle event is the tone of the left hand between them. Furthermore, let us assume that after the implementation of the physiological complexity the first event time will be 105 , and the third time 160 . The time of the middle event will then be changed to a value of $x$, thus $(110-100) /(150-100)=(x-105) /(160-105)$. All the events in the track of the left hand which do not match the tones on the heavy beats are interpolated in this way. The remaining two tracks, the right hand and the controller, are then adjusted in the same way (i.e. by linear interpolation according to heavy beats of the left hand). This method of modification ensures that the rhythm (the heavy beats of the left hand) will have the desired physiological complexity, but also that the composition will not disintegrate in the sense that the order and the relative temporal distances of the other MIDI events will be retained as reasonably as possible.

High-quality piano samples ${ }^{15}$ will be added to the recordings modified in this way (quantized and subsequently altered using rhythm disturbance of various amplitudes).

The modified recordings will then be verified in a pilot study by a group of respondents.

The following five recordings were selected for the questionnaire survey ${ }^{16}$ : a quantized ${ }^{17}$ one, a humanized ${ }^{18}$ one and three more recordings containing implemented physiological complexity. Three levels of disturbance were chosen - phc $=0.4$, phc $=0.8$, phc $=1.0 .{ }^{19}$

A hypothesis was formulated: Let us suppose that the recordings with the implemented rhythm disturbance of any offered amplitude do not disturb (i.e. they

\footnotetext{
15 Digital audio workstation Logic Pro X, sample Steinway Grand Piano.

16 Appendix No. 1.

${ }_{17}$ Quantization: rounding parameters of MIDI recordings on a pre-set grid. It is elimination of inaccuracies in the time of the tone beginning, its duration, the pitch, intensity and others.

${ }_{18}$ Humanization: intentional misalignment of parameters of accurate and computer-readable musical transcription in such a way that its computer playback will be close to performance of a live artist. ${ }^{19} \mathrm{phc}=$ level of physiological complexity
} 
are "liked") and they are perceived positively in terms of rhythmic accuracy. If it is possible to disprove the hypothesis, the level of the implemented disturbance perceived as disturbing listening should be identified. Let us suppose that the quantized recording will be marked as rhythmically accurate and the humanized recording will be the most liked by the respondents.

Modified recordings were played to 50 respondents on a sufficiently highquality sound speaker system under controlled conditions. Each of the volunteers heard five numbered samples (quantized version, humanized version and three versions with different amplitudes of rhythmic noise), always the same section of the track, with different amplitudes of rhythmic noise, in random order, while no two of them were alike. It was possible to go back to each recording. The respondents worked with instructions to focus on the rhythm, but at the same time they were notified that it was not the accuracy of the answers but the subjective perception of the rhythm that was being monitored. The first task was to order the recordings in a numbered list according to their rhythmic accuracy, from the rhythmically most accurate to the least accurate. The second task was to order the recordings in a numbered list from the one that the respondents liked best to the one that they liked least, while this rating did not have to correspond with rhythmic accuracy. In the third and fourth questions the respondents answered why they liked the given recording best, or what they found disturbing in any of the recordings.

The outcome of the statistically processed data should determine which intensity of disturbance is already audible, yet does not disturb listening.

\section{Results}

The answers of the 50 respondents aged 18-50 were gathered. All except one are amateur musicians. All except 7 respondents play a musical instrument; most commonly the piano (25), the guitar (13) and the recorder (13). Other musical instruments are played by fewer than ten respondents. In order to filter out disturbances, the reasons why the respondents'listening has been disturbed are examined.

In total, twenty-four respondents (almost a half) claimed that recording no. 4 ( $\mathrm{phc}=1.0$ ) was disturbing; they mostly gave reasons related to the rhythm (tempo changes, acceleration, "legging behind", unbalance...). Fourteen respondents claimed that recording no. $2(\mathrm{phc}=0.8)$ was disturbing; their reasons were also mostly related to the rhythm. Recording no. 1 ( $\mathrm{phc}=0.4$ ) was disturbing only to four respondents, two of them explained that it was rhythmically inaccurate and two claimed it was too fast. Recording no. 3 (quanta) was disturbing to two respondents for unclear reasons. R recording no. 5 (human) was also disturbing to two respondents. 
It can be stated that $\mathrm{phc}=1$ is too large an amplitude, which about a half of the respondents find disturbing. While phc $=0.8$ is also beyond acceptable, phc $=0.4$ is acceptable. Therefore, $\mathrm{phc}=0.4$ or phc $=0.5$ have been chosen for the therapeutic test. As it was expected, only a very small number of respondents have found quantized and humanized recording disturbing (both types of recordings are commonly used nowadays).

To summarize the results regarding the order of the recordings according to their rhythmic accuracy and liked preference, the presented graph has been created (like-accurate.png). The proportion of the respondents who mentioned the recording in this place is colour-coded in the given column. For example, the column "most accurate" has 48 percent of blue colour, which means that 48 percent of the respondents claimed that the humanized version was most accurate etc. Most respondents preferred humanized and quantized versions; both have approximately the same results. $\mathrm{Phc}=1.0$ indicates "least liked".

The humanized recording, not the quantized one, has been marked as most accurate by the respondents. The following order is clear; emotionally, the second most preferred accurate recording is the quantized version; followed by phc $=$ 0.4 , phc $=0.8$ and $\mathrm{phc}=1.0$ in the correct order.

The fact that more respondents claimed that the humanized version was most accurate than respondents preferred the humanized version is interesting.

Among the reasons given why a recording was most preferred, the claim that it appears natural and flowing usually prevails. Among the reasons for what disturbs the recordings, rhythmic imperfections are mostly mentioned.
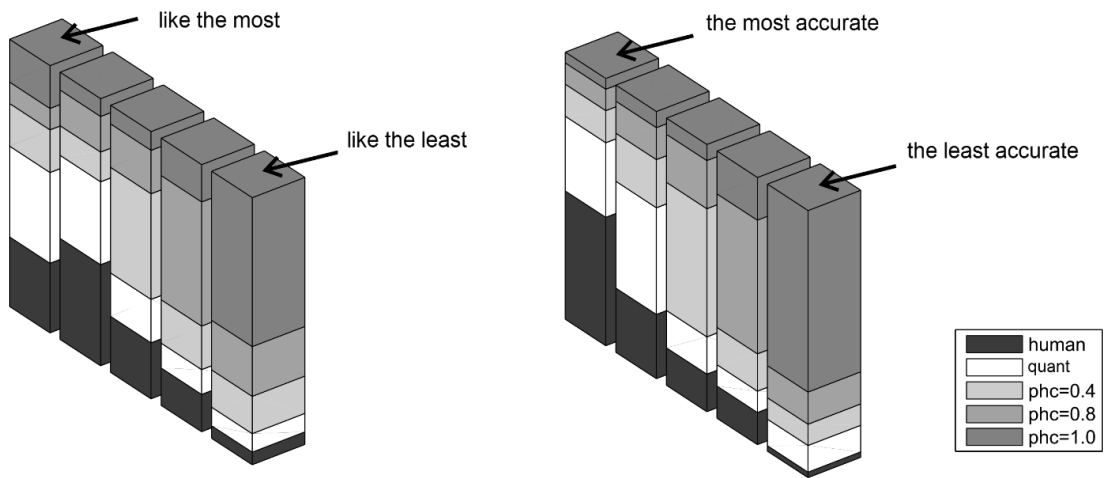

- Explanatory notes

human humanized version

quant quantized version

$\mathrm{phc}=\mathrm{x} \quad$ level of physiological complexity is $\mathrm{x}$ 


\section{Discussion}

The evaluation of the pilot-study results has shown some surprising findings. The humanized recording has been identified as rhythmically most accurate, although the most accurate version is actually the quantized one. Furthermore, it was assumed that there would be more respondents preferring the humanized recording than those who would mark it rhythmically most accurate. These findings prove how subjective the perception of the rhythm is and may limit the results of the study. The composition of the respondent group, the kind of music selected or the conditions in which it is reproduced (i.e. use of headphones) are among some of the other limitations.

The software created to implement physiological complexity into Mozart's Sonata Facile (Piano Sonata No. 16 in C major) enabled us to obtain the altered recordings which will be used in our music therapy practice for patients with neurodegenerative diseases.

Based on the research preparation phase, an experimental design of the quantitative was created, enabling cooperation between neurologists, psychiatrists and music therapists.

It is assumed that the method may prove effective not only in Alzheimer's disease patients (i.e. neurodegenerative diseases), but also in patients with neurodevelopmental disorders, especially in ADHD children and children with autism spectrum disorders. It is our intention to attempt to create a holistic music therapy method that would comprise work with music stimuli with implemented physiological complexity.

\section{Conclusion}

This study attempted to apply and spread new rehabilitation methods by Nicholas Stergiou. Our strategy implemented the pink-noise physiological complexity as a rhythmic disorder directly into parts of musical compositions.

The central thesis was the assumption that disease is a result of reduction or absence of physiological complexity. Rehabilitation strategies should seek to restore it by exposure to musical stimuli into which physiological complexity has been artificially injected by changing the duration of individual bars, resulting in the resemblance between the final time line and the time line of RR intervals on ECG.

It was found out that building physiological complexity into MIDI files using our software is relatively easy. It was verified by the pilot study that the upper margin of the amplitude applicable in therapy is phc $=0.5$. 


\section{Appendix No. 1}

Mozart: Sonata Facile, K. 545, the pilot study of altered recordings

Dear colleagues,

We appreciate your participation in our research focused on specific rehabilitation strategies for $\mathrm{AD}$ patients. The project is now in its first phase, in which altered recordings of Mozart's Sonata Facile K. 545 are piloted.

Please read the instructions first:

1) You are going to listen to five recordings. No two recordings are identical.

2) The recordings are marked with numbers $1-5$. You can go back and listen to them again as you choose.

3) When listening, focus especially on the rhythm of each piece.

4) It is not our aim in the pilot study to evaluate how correct your answers are, but your subjective perception of the rhythm.

Are you an amateur or a professional musician?

Which musical instruments do you play?

1) Order the recordings according to the accuracy of their rhythm. (For example, 2-4-1-5-3 means that recording no. 2 seems rhythmically most accurate to you ... and recording no. 3 least accurate.)

2) Order the recordings according to your preference/ which one you like most. (For example, 2-4-1-5-3 means that you like recording no. 2 the most ... and that you like recording no. 3 least. The order does not need to be related to the accuracy of the rhythm.).

3) Indicate/ Explain why you like/ prefer the recording(s) from the previous question:

4) Is there anything you find disturbing in the recordings? If so, please indicate/ explain why and which recordings these are. 


\title{
Appendix No. 2
}

Recordings of musical stimuli

No. 1 phc $=0,4$

No. 2 phc $=0,8$

No. 3 quant

No. 4 phc $=0,1$

No. 5 human

No. 6 phc $=0,2$

\section{Experimental Design and Technical Tools for the Research of Musical Stimuli with Artificially Implemented Complexity Used in the Rehabilitation of Alzheimer's Disease Patients}

\begin{abstract}
This study focuses on identifying new and effective rehabilitation strategies for patients with Alzheimer's disease, which relies on the empirically confirmed effect of musical stimuli. The strategies were inspired by studies of new rehabilitation methods designed by Nicholas Stergiou (Biomechanics Lab, University of Nebraska in Omaha), based on signals that contain artificially incorporated physiological complexity (e.g. pink noise). The physiological signals of a healthy organism contain a certain degree of such complexity. The first phase of the research includes the creation of software in a MIDI format, which enabled the implementation of this complexity into recordings of classical music, and its piloting on a "healthy" population. The following phase will examine the effects of these recordings on patients with $\mathrm{AD}$ (in collaboration with neurologists in diagnostics).
\end{abstract}

Návrh experimentu a technické nástroje pro výzkum hudebních podnětů s uměle implementovanou komplexitou fyziologického typu užité pro rehabilitaci pacientů s Alzheimerovou chorobou

\section{Abstrakt}

Výzkum se zaměřuje na hledání nových účinných rehabilitačních strategií pro pacienty s Alzheimerovou chorobou, které se opírají o empiricky potvrzené působení hudebních podnětů. Tyto strategie jsou inspirovány studiemi nových rehabilitačních metod navržených Nicholasem Stergiou (Biomechanics Lab, 
University of Nebraska in Omaha), jež jsou založeny na signálech, které cíleně obsahují uměle zakomponovanou fyziologickou komplexitu (např. typu růžového šumu). Jde o to, že fyziologické signály zdravého organismu vykazují právě jistou míru této komplexity. První fáze výzkumu zahrnuje tvorbu softwaru ve formátu MIDI, který umožňuje tuto komplexitu zabudovat do nahrávek klasické hudby, a pilotování takto upravených nahrávek na „zdravé“ populaci. Následující fáze bude zkoumat vliv těchto hudebních podnětů na pacienty s Alzheimerovou chorobou (spolupráce s neurology v diagnostice).

\section{Keywords}

ADHD; Alzheimer's disease; autism; new rehabilitation strategies; physiological complexity of pink noise; software MIDI.

\section{Klíčová slova}

Alzheimerova choroba; ADHD; autismus; rehabilitační strategie; fyziologická komplexita typu růžového šumu; software MIDI. 